Gazi University
Journal of Science
http://dergipark.gov.tr/gujs

\title{
The Effects of Anchor Configurations and Field Characteristics on Anchored Diaphragm Walls
}

\author{
Anu JAMES $^{1, *}$ (D), Babu KURIAN ${ }^{2}$ (D) \\ ${ }^{1}$ Research Scholar (M.G. University), Department of Civil Engineering, Mar Athanasius College of Engineering, 686666, Kerala, India. \\ ${ }^{2}$ Research Supervisor (M.G. University), Department of Civil Engineering, Mar Athanasius College of Engineering, 686666, Kerala, India.
}

\author{
Highlights \\ - Parametric analysis on anchored diaphragm wall. \\ - Studies to quantitatively comprehend influence of various wall configurations. \\ - Parametric studies on anchor length, prestress and inclination. \\ - Comparative charts to perceive proper parametric combinations. \\ - Influence of various parameters on deformations, axial capacity and flexural capacity.
}

\begin{tabular}{l} 
Article Info \\
\hline Received: $24 / 04 / 2019$ \\
Accepted: $15 / 04 / 2020$ \\
\\
Keywords \\
\hline Diaphragm wall \\
Parametric analysis \\
Anchor configuration \\
Anchor prestress \\
Design guidelines
\end{tabular}

\section{INTRODUCTION}

Recent economic developments and present-day technologies like mass rapid transits, underground tunnels etc. demand need for more working space in urban areas without disturbing existing infrastructures. Constructive utilisation of underground space is the most effective solution for this space constraint. Major concerns regarding underground constructions are excessive ground movements affecting stability of adjacent structures. Excavations within close proximity of infrastructures should satisfy strict safety and serviceability criteria and deformations must be within permissible limits. Techniques like diaphragm walls can provide more rigidity to excavation supports due to the structural advantages. Greater care should be given for the excavation process as the failure of diaphragm walls and supporting facilities may cause devastating consequences in social, economic and environmental front. This makes reliable estimates of deformations and forces induced by excavations a necessity.

\begin{abstract}
walls are the ideal solution for productive utilisation of underground space to meet configurations has substantial impact on economy, time and performance of diaphragm wall projects. Unsatisfactory implementation of such retaining systems during or after construction may cause heavy causalities such as loss of life and damage to adjacent infrastructures. Practical significance of excavation induced deformations is large due to its potential damage to adjacen structures. Hence, reliable estimates of excavation related responses are vital for construction and implementation of embedded diaphragm walls. This paper presents results of parametric analysis characteristics. Numerical studies are carried out to comprehend the influence of factors like ground conditions, excavation geometry and anchor characteristics. Walls embedded in cohesive and non-cohesive soils with varying ground water locations are considered for analysis. Anchor features including length, inclination and axial prestress are varied in combination with the above parameters. The effects of these factors and their combined influence on the deformation, flexural strength and axial capacity of diaphragm walls are determined and evaluated. Numerical analyses demonstrate the variations of wall responses with different combinations of influencing factors. Optimal configurations of diaphragm wall and anchor system for different ground conditions can be perceived from the result charts.
\end{abstract}


Lateral displacements and vertical settlements may occur simultaneously for an embedded wall which can directly affect the stability of adjacent structures. Boscardin and Cording [1] found that the vertical and horizontal deformation considerations are vital for the determination of damage level induced by the structure, making reliable evaluations of vertical forces developing on walls a critical parameter. The lateral displacements are also equally important, as, if not within safe acceptable limits will result in failure of structure itself, as well as surrounding infrastructures. Most of the studies assessing the influence of various factors affecting the performance of excavations and slurry walls make use of analytical as well as numerical simulations. The influence of various parameters on the performance of deep excavations are studied by many researchers. Clough et al. [2] compared braced excavations and tie-back walls to study the effects of anchor spacing, stiffness, excavation depths, wall rigidity etc. using finite element analysis. They concluded that increasing anchor stiffness and wall rigidity can reduce wall movements, but widely spaced tie-back results in stress concentrations at anchor levels. Goh [3] carried out parametric finite element studies to evaluate effects of wall properties and excavation geometries like excavation width, embedded depths etc. on deep excavations in clay. The study showed that embedded depth, wall stiffness and thickness of clay layer are the primary factors affecting basal stability. Field performance of tie-back excavations are studied by various researchers [4-7]. Garvin and Boward [4] studied the cut and cover construction of a tie back diaphragm wall supporting an $8 \mathrm{~m}$ deep excavation. Movements and ground water levels during the construction process were monitored. The maximum lateral movements of wall were observed to be between 10 to $20 \mathrm{~mm}$. The investigations on anchored walls by Winter et al. [5] also showed minor wall displacements with a maximum value of horizontal wall displacement of $0.15 \% \mathrm{H}$. Effects of anchor rods on diaphragm walls were studied by Yajnheswaran et al. [8]. Analysis results with different locations of anchor rods for a berthing structure were compared with structures without anchors. Study revealed that providing anchor rods at optimum locations will improve stability. Yajnheswaran et al. [9] analysed two braced diaphragm wall sections with non-uniform wall stiffness using Plaxis. The loads and displacements developed were compared with the previous study [8] to conclude that the reduction in bending moment is accompanied by increased wall movements which however will depend on the degree of excavation support facilities. Comparison of specifications illustrated in Eurocodes and Polish codes was performed for cantilevered, strutted and anchored diaphragm walls by Lewandowska and Czajewska [10]. Ou [11] and FHWA [12] provide recommendations on anchor configurations such as installation angles and length requirements.

Teo \& Wong [13] reported the benefits of hardening soil model (HS) over the Mohr Coulomb (MC) model for soil behaviours of deep excavations. The results claim that the HS model cover inadequacies of MC model. Hoe [14] reviewed suitability of Mohr-Coulomb model and soil hardening model and compared with field measured data and observed that HS model provided more accurate representation for deformations. The MC model is however still being implemented for analysis of excavations and with reasonable accuracy [15-20]. 3D effects of excavations in non-cohesive soils on wall deflections were studied by Hsiung, Yang et al. [21]. The MC model was found to provide acceptably accurate estimates for wall and ground deformations. Houhou, Emeriault et al. [19] performed back analysis of excavation induced responses regarding deformations and support forces. Acceptable agreement was obtained between the computed and measured results, with excavation simulated using simple MC model.

Diaphragm walls being deep embedded structures, lateral deformations and vertical settlements are equally important and consequently the flexural and axial capacity should be counted. For the accurate response prediction studies, normal axial forces acting on the wall should be considered along with bending moments and shear forces. The current study attempts to estimate the design parameters of an anchored diaphragm wall by conducting numerical analysis to evaluate the effects of influencing factors. Soil properties and ground water conditions are varied in combination with different features defining anchor configurations. Response estimations from the study helps to recognise areas requiring improvements for any particular tie-back wall project and thereby aids to effectively formulate design procedures. Location of ground water level (g.w.l) is chosen as a varying factor in this response estimation study. Every numerical case is performed for four locations of g.w.l so that the response predictions are more practical. The study specially focusses on the quantitative effects of the combined influence of different wall, support and field characteristics. 
Even though the literature studies show the effects of various anchor configurations, the combined effects are not portrayed efficiently. Barely any literature is available which consider the effects of ground water level locations, which can be a critical factor in response prediction analysis. The analysis charts demonstrating the variations with different parameters along with various water table locations, cover these shortfalls so that more practical and reliable estimates of wall responses can be obtained. The parameters such as anchor force and anchor length are denoted in terms of percentage increase, so that the possible relative variations can be easily understood.

\section{NUMERICAL STUDY}

Diaphragm walls with prestressed anchors will help to significantly reduce wall deformations. Numerical parametric analysis is conducted to assess the quantitative impacts of various features of anchored diaphragm walls. The factors influencing deformations and load development include geometry of excavations, stiffness of wall and support, properties of anchor etc. The parameters considered herein are type of soil, location of ground water, anchor prestress force, anchor inclination and anchor length. The structural analysis is carried out by means of finite element modelling with Plaxis $2 \mathrm{~d}$. Diaphragm walls are simulated by elastic plate element, defined by parameters such as normal and bending stiffness, Poisson's ratio etc. Mohr-Coulomb soil model was used to simulate active and passive earth mass. Anchor rods are modelled by node to node anchor elements and anchor grout body by geogrids in Plaxis directory.

To study the variations in diaphragm wall responses with varying ground water level, four different ground water level locations are considered. This consideration must be a critical parameter in any geotechnical response estimation studies as hydrostatic pressure has an immense influence on the lateral loads, especially for retaining structures embedded deep in to the ground. All the field and wall parameters considered as variants in the study are in turn combined with the different g.w.l so as to identify optimal configurations for diaphragm wall projects. The ground water level locations considered are: one at every one third of total excavation depth and dry ground state $\left(W_{L 1}, W_{L 2}, W_{L 3}\right.$ and $\left.W_{L D}\right)$ as shown in Figure 1. $D_{x}$ and $D_{m}$ represent the final excavation depth and embedded depth respectively.

The parameters and symbols used and the anchor configurations are detailed in Figures 1 and 2. Both cohesive and non-cohesive soil profiles are numerically analysed for the response predictions. The details of soil data are summarised in Table 1. The material properties of the wall are fixed as: Modulus of elasticity, $E_{w}=30 \mathrm{~N} / \mathrm{mm}^{2}$, Poisson's Ratio, $\mu_{w}=0.19$, thickness $=800 \mathrm{~mm}$. The total wall height is $10 \mathrm{~m}$ with a final retained height $\left(D_{x}\right)$ of $6 \mathrm{~m}$ and embedded depth $\left(D_{m}\right)$ of $4 \mathrm{~m}$, with anchor installed at $3.5 \mathrm{~m}$ from the ground level and spaced $3 \mathrm{~m}$ horizontally [11]. Maximum values of lateral deflection, bending moments, axial forces and shear forces are computed from analysis.
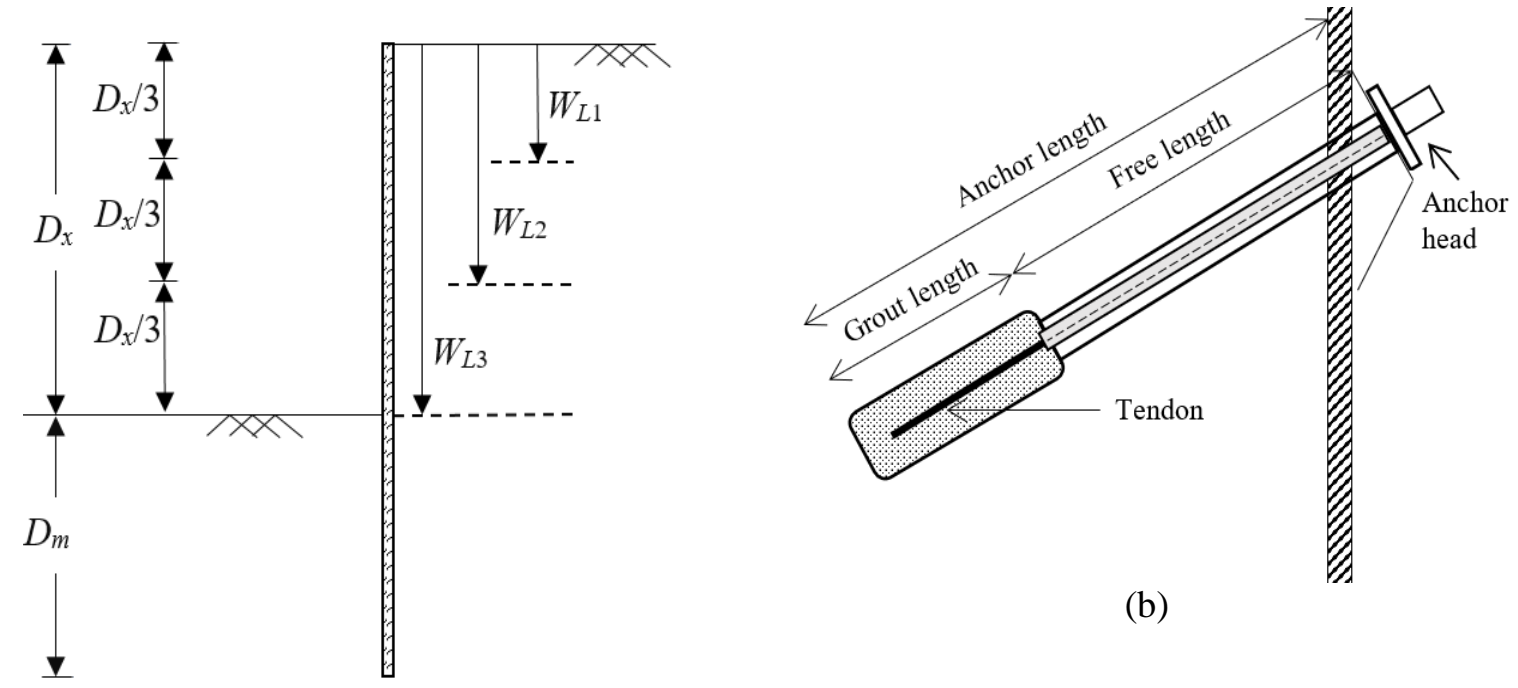

(b)

(a)

Figure 1. (a) Symbols used (b) Anchor configurations 
Table 1. Soil properties considered for study

\begin{tabular}{|l|l|l|}
\hline Soil profile & A1 & A2 \\
\hline Cohesion, $C\left(\mathrm{kN} / \mathrm{m}^{2}\right)$ & 10.0 & 00.3 \\
\hline Angle of internal friction, $\phi($ degrees $)$ & 27.5 & 35.0 \\
\hline Modulus of elasticity, $E\left(\mathrm{kN} / \mathrm{mm}^{2}\right)$ & 30.0 & 70.0 \\
\hline Dilatancy angle, $\psi$ & 0.00 & 05.0 \\
\hline Poisson's' ratio, $\mu$ & 00.3 & 0.35 \\
\hline$\gamma_{\text {sat }}\left(\mathrm{kN} / \mathrm{m}^{3}\right)$ & 19.0 & 19.0 \\
\hline
\end{tabular}

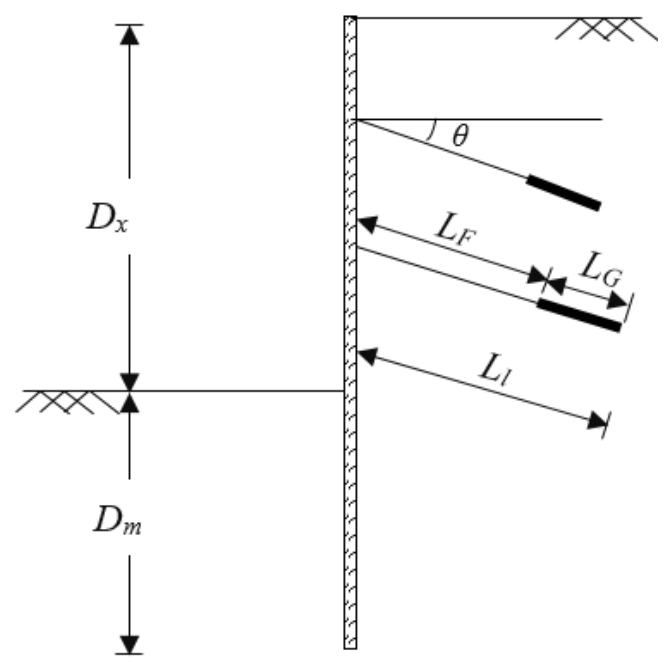

Figure 2. Parameters considered for analysis

A major concern regarding tie back walls in urban area is the requirement of area beyond the boundary to install permanent anchors, making length of anchors a vital parameter. Anchor length includes the load bearing grout length and free length carrying tendon casing. The preloaded tendons should be able to move freely within the free length zone. If the free length is too small, soil induced stresses near to grout length may adversely affect wall stability. Anchor capacity will also get affected with lower values of free lengths due to the possible development of larger stresses. For grout body, the bonding forces with prestressing tendons and the anchorage forces with surrounding earth mass should be adequate enough to attain full anchor strength. Inclination of prestressed anchors is another significant parameter affecting the capacity of supporting system. Inclination along loading can provide maximum anchor effectiveness. Installation angle from horizontal cannot be too small since it is better to penetrate deep, to attain maximum strength. Installation angles should not be too large also as it may result in increased vertical force components on the wall, causing undesirable ground and wall settlements. Hence anchors should be installed within a safe range. Prestressing of anchors help to significantly reduce wall deformations. Anchor heads transmit the preloads which is transferred to the ground by the bonding force of grout body.

An initial analysis is performed on cantilevered walls to decide on the feasible parametric combinations of different embedded and excavation depths. To comprehend the influence of different wall heights, unsupported diaphragm walls with three different embedded depths $(4 \mathrm{~m}, 5 \mathrm{~m}, 6 \mathrm{~m})$ in combination with six different excavation depths $(6 \mathrm{~m}$ to $8.5 \mathrm{~m})$ are analysed. These combinations are again in turn analysed for the four ground water level locations. Some of the combinations of excavation and embedded depths are found to be unstable. The feasible parametric combinations are denoted in Figure 3, highlighting the necessity of lateral supports. If a code representing an embedded depth denoted in the graph legend is missing, that particular combination is unstable or failed during the analysis process. The extreme combination of excavation depth and embedded depth is selected for the further analysis of anchored walls. 


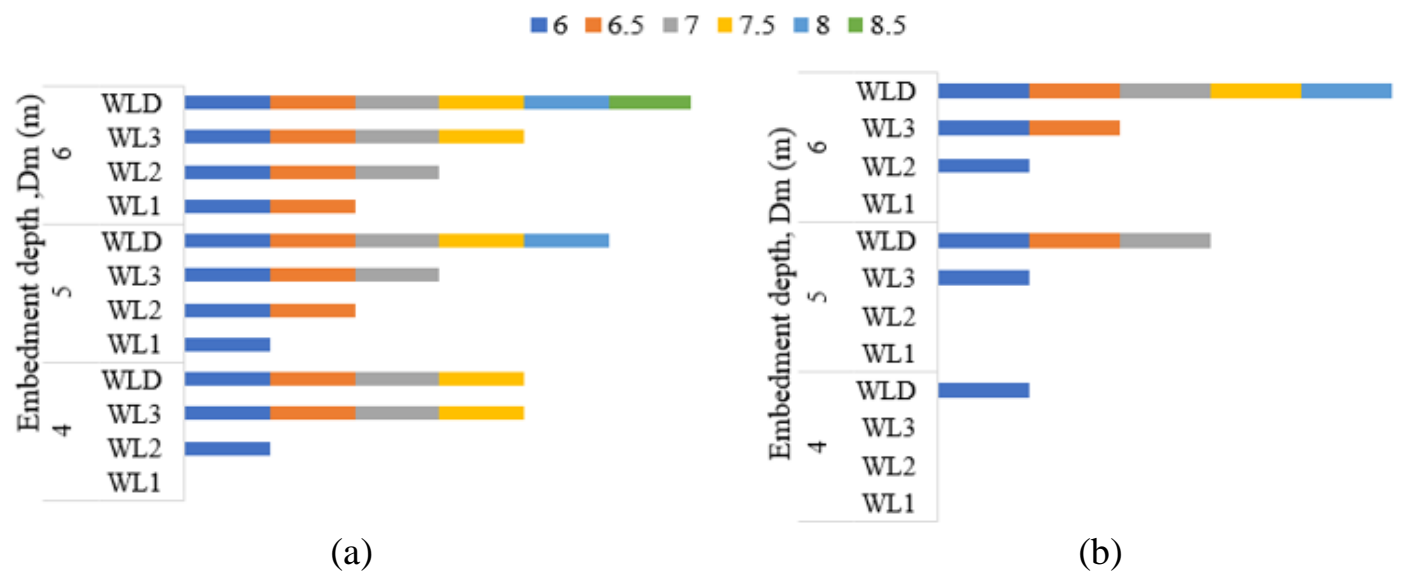

Figure 3. Feasible combinations from cantilevered wall analysis (a) Al (b) A2

The recommended installation angles for anchors with horizontal is between 10 degrees to 45 degrees [11, 12]. The commonly utilised installation angles are 15 degrees to 30 degrees to minimise vertical anchor loads. Steeper inclinations than these can be used to avoid adjacent foundations or other underground utilities where there are numerous infrastructures [12]. Grouting of anchors less than 10 degrees are not common unless special grouting techniques can be used [12].

For the safety and stability of the retaining structure, the grout length or the fixed length of the anchor should be placed at a distance of at least $2 \mathrm{~m}$ outside the possible failure surface [11]. According to FHWA [12] this distance required from failure plane is $1.5 \mathrm{~m}$ or $0.2 D_{x}$. Based on these criteria, the minimum required unbonded lengths computed are listed in Table 2. The grout length of anchor is fixed at $4 \mathrm{~m}$. The different commonly considered failure zone surfaces are the those starting from excavation bottom, assumed support and bottom of the wall. Failure zone starting from the bottom of retaining wall is the most conservative [11] and hence is selected for the study. A sample of analysis model is given in Figure 4 showing finite element mesh and boundary conditions. For the mesh discretisation, fine mesh option in Plaxis is used for analysis.

Table 2. Anchor length requirements

\begin{tabular}{|l|l|l|l|l|l|l|}
\hline \multirow{2}{*}{ Anchor angle } & \multicolumn{2}{l|}{ Minimum free length required } & \multicolumn{4}{l|}{ Anchor length } \\
\cline { 2 - 7 } & A1 & A2 & $\begin{array}{l}\text { Anchor length } \\
\text { notation }\end{array}$ & $\begin{array}{l}\text { Free } \\
\text { length }\end{array}$ & $\begin{array}{l}\text { Fixed } \\
\text { length }\end{array}$ & $\begin{array}{l}\text { Total } \\
\text { length }\end{array}$ \\
\hline $15 \mathrm{deg}$. & 5.00 & 4.57 & $L_{0}$ & 6 & 4 & 10 \\
\hline $30 \mathrm{deg}$. & 4.95 & 4.50 & $L_{1}$ & 7 & 4 & 11 \\
\hline $40 \mathrm{deg}$. & 4.97 & 4.58 & $L_{2}$ & 8 & 4 & 12 \\
\hline- & - & - & $L_{3}$ & 9 & 4 & 13 \\
\hline- & - & - & $L_{5}$ & 10 & 4 & 14 \\
\hline
\end{tabular}

Anchor inclinations of $15^{\circ}, 30^{\circ}$ and $40^{\circ}$ with horizontal and five different anchor lengths are considered for parametric analysis so that effects of larger dragging down forces can also be assessed. The different combinations evaluated are summarised in Table 3. All these cases are in turn analysed for four ground water locations. The anchor length is denoted by $L_{l}$ with subscript ' $l$ ' representing length increment in metres from the minimum length of $10 \mathrm{~m}$. Five different prestressing loads are considered starting from a minimum value of $120 \mathrm{kN}$ denoted by $F_{0}$ and further incremented by 20,40,60 and $80 \%$. The prestressing force applied is denoted by $F_{x}$, ' $x$ ' representing the percentage increment from $F_{0}$. This pattern is followed to understand the response variations relative to percentage variations in anchor force. 

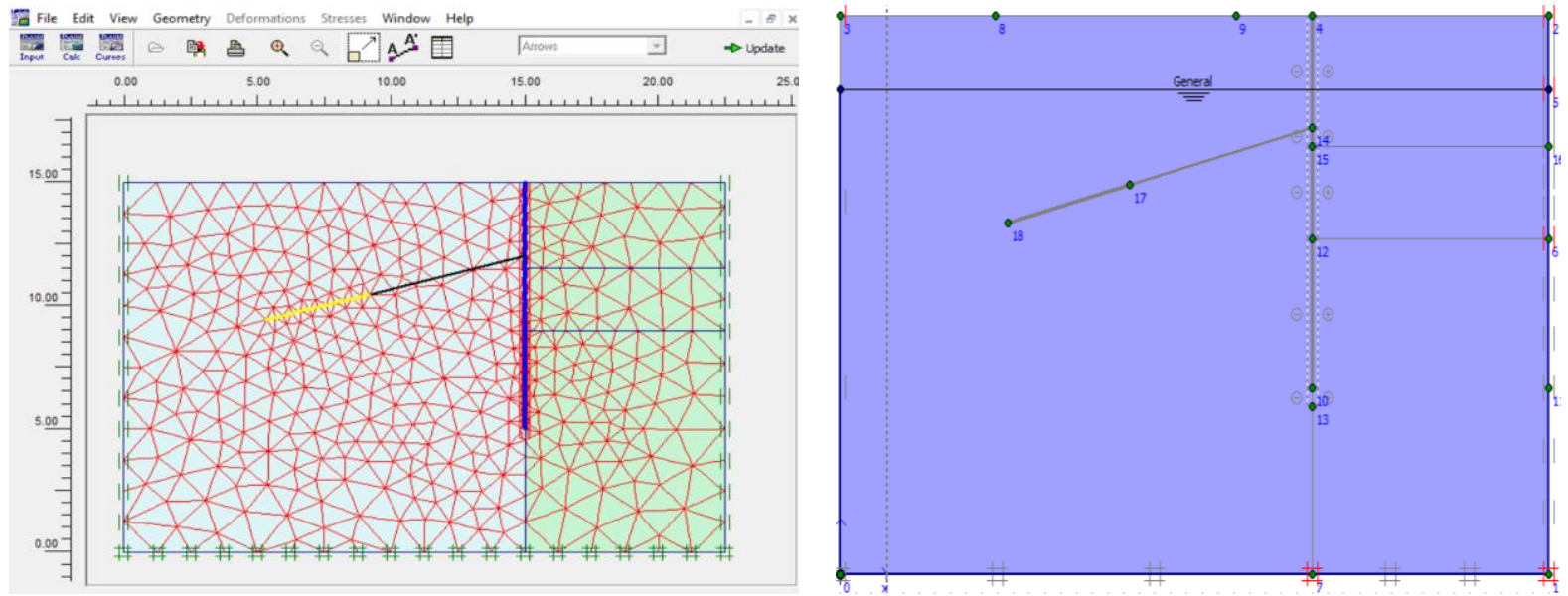

Figure 4. Finite element model

Table 3. Combinations chosen for parametric analysis

\begin{tabular}{|c|c|c|c|c|c|c|c|c|c|c|c|c|c|c|c|c|}
\hline \multirow{3}{*}{$\begin{array}{l}\text { Soil } \\
\text { type }\end{array}$} & \multirow{3}{*}{$\begin{array}{l}\text { Anchor } \\
\text { inclination }\end{array}$} & \multicolumn{15}{|c|}{ Anchor prestress, $F_{x}(\mathrm{kN})$} \\
\hline & & \multicolumn{3}{|c|}{$F_{0}$} & \multicolumn{3}{|c|}{$F_{20}$} & \multicolumn{3}{|c|}{$F_{40}$} & \multicolumn{3}{|c|}{$F_{60}$} & \multicolumn{3}{|c|}{$F_{80}$} \\
\hline & & \multicolumn{15}{|c|}{ Anchor length, $L_{l}(\mathrm{~m})$} \\
\hline \multirow{3}{*}{ A2 } & $15^{0}$ & $L_{1}$ & $L_{2}$ & $L_{3}$ & - & - & - & $L_{1}$ & $L_{2}$ & $L_{3}$ & - & - & - & $L_{1}$ & $L_{2}$ & $L_{3}$ \\
\hline & $30^{0}$ & $L_{1}$ & $L_{2}$ & $L_{3}$ & - & - & - & $L_{1}$ & $L_{2}$ & $L_{3}$ & - & - & - & $L_{1}$ & $L_{2}$ & $L_{3}$ \\
\hline & $40^{\circ}$ & $L_{1}$ & $L_{2}$ & $L_{3}$ & - & - & - & $L_{1}$ & $L_{2}$ & $L_{3}$ & - & - & - & $L_{1}$ & $L_{2}$ & $L_{3}$ \\
\hline \multirow{3}{*}{ A1 } & $15^{0}$ & $L_{0}$ & $L_{2}$ & $L_{5}$ & $L_{0}$ & $L_{2}$ & $L_{5}$ & $L_{0}$ & $L_{2}$ & $L_{5}$ & $L_{0}$ & $L_{2}$ & $L_{5}$ & $L_{0}$ & $L_{2}$ & $L_{5}$ \\
\hline & $30^{\circ}$ & $L_{0}$ & $L_{2}$ & $L_{5}$ & $L_{0}$ & $L_{2}$ & $L_{5}$ & $L_{0}$ & $L_{2}$ & $L_{5}$ & $L_{0}$ & $L_{2}$ & $L_{5}$ & $L_{0}$ & $L_{2}$ & $L_{5}$ \\
\hline & $40^{\circ}$ & $L_{0}$ & $L_{2}$ & $L_{5}$ & $L_{0}$ & $L_{2}$ & $L_{5}$ & $L_{0}$ & $L_{2}$ & $L_{5}$ & $L_{0}$ & $L_{2}$ & $L_{5}$ & $L_{0}$ & $L_{2}$ & $L_{5}$ \\
\hline
\end{tabular}

\section{RESULTS AND DISCUSSIONS}

The ultimate aim of the numerical analysis is to evaluate the combined influence of various parameters on the deformations, axial capacity and flexural capacity of anchored diaphragm walls.

\subsection{Effects on Deformation Characteristics}

Diaphragm walls due to its comparatively higher rigidity helps to reduce excavation induced deformations. Use of prestressed anchors aid in the further reduction of unfavourable wall deflections. The numerical values of lateral deflections obtained from the analysis are detailed in Tables 4 and 5. The variations in wall deformations with different influencing parameters are evaluated and the variations are illustrated in Figures 5-8. For accurate prediction of the wall deflections, the combined influence of the parameters need to be considered.

For an anchor inclination of $15^{\circ}$ combined with a prestressing force $F_{0}$, lateral wall deflection shows a reduction to $65 \%$, when the anchor length varies from $L_{0}$ to $L_{5}$. The reference values are listed in Table 5 . This variation is $63 \%$ and $59 \%$ for anchor inclinations of $30^{\circ}$ and $40^{\circ}$. For a prestressing force of $F_{20}$ these variations corresponding to the length increment from $L_{0}$ to $L_{5}$ and anchor inclinations $15^{\circ}, 30^{\circ}$ and $40^{\circ}$ are $66.3 \%, 62.96 \%$ and $59.79 \%$ respectively. The above results are obtained for analysis considering the location of g.w.l at $W_{L 1}$. The rate of percentage variation of lateral deflections shows a reduction with increments in anchor inclinations. 
Table 4. Lateral deflections ( $\mathrm{mm}$ ) computed for soil profile A2

\begin{tabular}{|c|c|c|c|c|c|c|c|c|c|c|}
\hline \multirow{2}{*}{\multicolumn{2}{|c|}{$\begin{array}{l}\text { Anchor } \\
\text { inclination } \\
\text { Anchor length }\end{array}$}} & \multicolumn{3}{|c|}{15 degrees } & \multicolumn{3}{|c|}{30 degrees } & \multicolumn{3}{|c|}{40 degrees } \\
\hline & & $L_{0}$ & $L_{2}$ & $L_{5}$ & $L_{0}$ & $L_{2}$ & $L_{5}$ & $L_{0}$ & $L_{2}$ & $L_{5}$ \\
\hline \multirow{4}{*}{$F_{0}$} & $W_{L 1}$ & 20.5 & 17.5 & 15.9 & 24.4 & 20.9 & 18.7 & - & - & 23.1 \\
\hline & $W_{L 2}$ & 14.2 & 12.2 & 11.2 & 16.8 & 15.2 & 13.4 & 20.5 & - & 16.6 \\
\hline & $W_{L 3}$ & 09.8 & 09.9 & 08.8 & 13.6 & 12.1 & 10.7 & 16.1 & - & 13.1 \\
\hline & $W_{L D}$ & 08.0 & 07.1 & 06.3 & 08.8 & 07.8 & 06.6 & 10.3 & - & 07.6 \\
\hline \multirow{4}{*}{$F_{20}$} & $W_{L 1}$ & 19.9 & 16.9 & 15.0 & 23.6 & 19.8 & 16.9 & 28.6 & 20.5 & 21.1 \\
\hline & $W_{L 2}$ & 13.4 & 11.5 & 10.3 & 15.7 & 13.6 & 11.9 & 18.5 & 17.1 & 14.8 \\
\hline & $W_{L 3}$ & 09.2 & 09.1 & 07.9 & 12.1 & 10.6 & 09.1 & 14.3 & 13.5 & 11.4 \\
\hline & $W_{L D}$ & 07.3 & 06.3 & 05.5 & 07.5 & 06.6 & 05.3 & 07.9 & 06.8 & 06.3 \\
\hline \multirow{4}{*}{$F_{40}$} & $W_{L 1}$ & 19.8 & 16.5 & 14.3 & 22.8 & 18.7 & 16.1 & 27.1 & 22.3 & 19.5 \\
\hline & $W_{L 2}$ & 12.8 & 10.9 & 09.4 & 14.2 & 12.2 & 10.4 & 17.0 & 18.1 & 13.8 \\
\hline & $W_{L 3}$ & 08.6 & 08.3 & 07.1 & 10.7 & 09.3 & 07.9 & 13.1 & 14.2 & 11.6 \\
\hline & $W_{L D}$ & 06.8 & 05.6 & 04.8 & 06.2 & 05.2 & 04.8 & 06.9 & 06.5 & 06.5 \\
\hline
\end{tabular}

Table 5. Lateral deflections ( $\mathrm{mm}$ ) computed for soil profile A1

\begin{tabular}{|c|c|c|c|c|c|c|c|c|c|c|}
\hline \multirow{2}{*}{\multicolumn{2}{|c|}{$\begin{array}{l}\begin{array}{l}\text { Anchor } \\
\text { inclination }\end{array} \\
\text { Anchor length }\end{array}$}} & \multicolumn{3}{|c|}{15 degrees } & \multicolumn{3}{|c|}{30 degrees } & \multicolumn{3}{|c|}{40 degrees } \\
\hline & & $L_{0}$ & $L_{2}$ & $L_{5}$ & $L_{0}$ & $L_{2}$ & $L_{5}$ & $L_{0}$ & $L_{2}$ & $L_{5}$ \\
\hline \multirow{4}{*}{$F_{0}$} & $W_{L 1}$ & 30.3 & 24.4 & 19.7 & 34.0 & 27.9 & 21.6 & 40.2 & 20.1 & 23.8 \\
\hline & $W_{L 2}$ & 20.9 & 16.6 & 13.0 & 22.0 & 17.7 & 15.6 & 24.2 & 18.5 & 17.3 \\
\hline & $W_{L 3}$ & 16.1 & 12.1 & 09.6 & 15.2 & 13.5 & 12.4 & 18.3 & 14.6 & 13.7 \\
\hline & $W_{L D}$ & 11.1 & 08.9 & 07.1 & 10.8 & 10.5 & 09.8 & 12.0 & 10.9 & 10.5 \\
\hline \multirow{4}{*}{$F_{20}$} & $W_{L 1}$ & 29.7 & 23.5 & 19.7 & 32.4 & 26.2 & 20.4 & 38.3 & 19.7 & 22.9 \\
\hline & $W_{L 2}$ & 20.3 & 15.7 & 13.0 & 19.8 & 16.7 & 15.0 & 22.3 & 17.7 & 16.8 \\
\hline & $W_{L 3}$ & 15.4 & 11.3 & 09.6 & 14.3 & 12.9 & 11.9 & 16.7 & 13.9 & 13.3 \\
\hline & $W_{L D}$ & 10.6 & 08.4 & 07.1 & 10.4 & 10.1 & 09.3 & 11.7 & 10.6 & 10.2 \\
\hline \multirow{4}{*}{$F_{40}$} & $W_{L 1}$ & 29.0 & 22.6 & 17.7 & 30.8 & 24.5 & 19.7 & 37.2 & 20.5 & 22.5 \\
\hline & $W_{L 2}$ & 19.5 & 14.7 & 11.4 & 18.1 & 16.0 & 14.5 & 21.2 & 17.1 & 16.5 \\
\hline & $W_{L 3}$ & 14.7 & 10.7 & 08.3 & 13.8 & 12.4 & 11.5 & 16.1 & 13.5 & 13.1 \\
\hline & $W_{L D}$ & 10.2 & 07.9 & 06.5 & 10.1 & 09.7 & 08.9 & 11.5 & 10.3 & 09.9 \\
\hline \multirow{4}{*}{$F_{60}$} & $W_{L 1}$ & 28.7 & 21.9 & 16.9 & 29.5 & 22.3 & 19.1 & 36.7 & 21.3 & 23.7 \\
\hline & $W_{L 2}$ & 18.7 & 13.7 & 10.9 & 17.5 & 15.6 & 14.1 & 21.1 & 17.1 & 17.5 \\
\hline & $W_{L 3}$ & 14.0 & 10.2 & 08.3 & 13.5 & 12.1 & 11.3 & 15.9 & 13.4 & 13.7 \\
\hline & $W_{L D}$ & 09.8 & 07.4 & 06.6 & 10.0 & 09.5 & 08.8 & 11.4 & 10.2 & 09.9 \\
\hline \multirow{4}{*}{$F_{80}$} & $W_{L 1}$ & 29.8 & 21.5 & 16.7 & 28.8 & 23.0 & 19.0 & 38.7 & 22.3 & 25.3 \\
\hline & $W_{L 2}$ & 19.2 & 13.1 & 10.9 & 17.3 & 15.2 & 14.0 & 21.8 & 18.1 & 19.3 \\
\hline & $W_{L 3}$ & 14.4 & 09.7 & 08.3 & 13.5 & 12.0 & 11.3 & 16.1 & 14.2 & 15.4 \\
\hline & $W_{L D}$ & 09.7 & 07.2 & 06.6 & 09.9 & 09.3 & 09.1 & 11.5 & 10.1 & 08.0 \\
\hline
\end{tabular}

Diaphragm walls embedded in profile A2 with anchors of length $L_{1}$ and $L_{2}$ and carrying the minimum prestressing force $F_{0}$ is found to fail, if the anchor inclination is $40^{\circ}$. For anchor inclinations of $15^{\circ}$ and $30^{\circ}$, when the anchor lengths vary from $L_{1}$ to $L_{3}$, the lateral deflection reduces to $77.53 \%$ and $76.43 \%$ respectively relative to that with length $L_{1}$. The reference values are given in Table 4 . For $F_{40}$, deflections will get reduced to $75.43 \%, 71.58 \%$ and $73.86 \%$ for anchor inclinations of $15^{\circ}, 30^{\circ}$ and $40^{\circ}$ respectively, when the anchor lengths vary from $L_{1}$ to $L_{3}$. The corresponding variations are $72.41 \%, 70.53 \%$ and $71.9 \%$ for a prestressing force of $F_{80}$.

For soil profile A1 with anchor prestress $F_{40}$, when g.w.l is assumed to drop to $W_{L 2}, W_{L 3}$ and $W_{L D}$ from $W_{L 1}$ the lateral deflection of wall reduces to $68.35 \%, 51.85 \%$ and $35.69 \%$ respectively for $15^{0}$ inclined anchors as listed in Table 5. For anchors with inclination of $30^{\circ}$, these variations are $61.11 \%, 44.41 \%$ and $32.1 \%$ 
and for $40^{\circ}$ inclined anchors the values are $58.22 \%, 43.6 \%$ and $30.54 \%$. For anchors inclined at $15^{\circ}$, the variations are $67 \%, 46.14 \%$, and $36.76 \%$, with further reduction to $66.5 \%, 51.25 \%$ and $31.64 \%$ for $30^{\circ}$ and $64.74 \%, 50 \%$ and $27.74 \%$ for $40^{\circ}$. A sample of variation of lateral deflection for an anchor length $L_{2}$ with various parameters are shown in Figure 5.

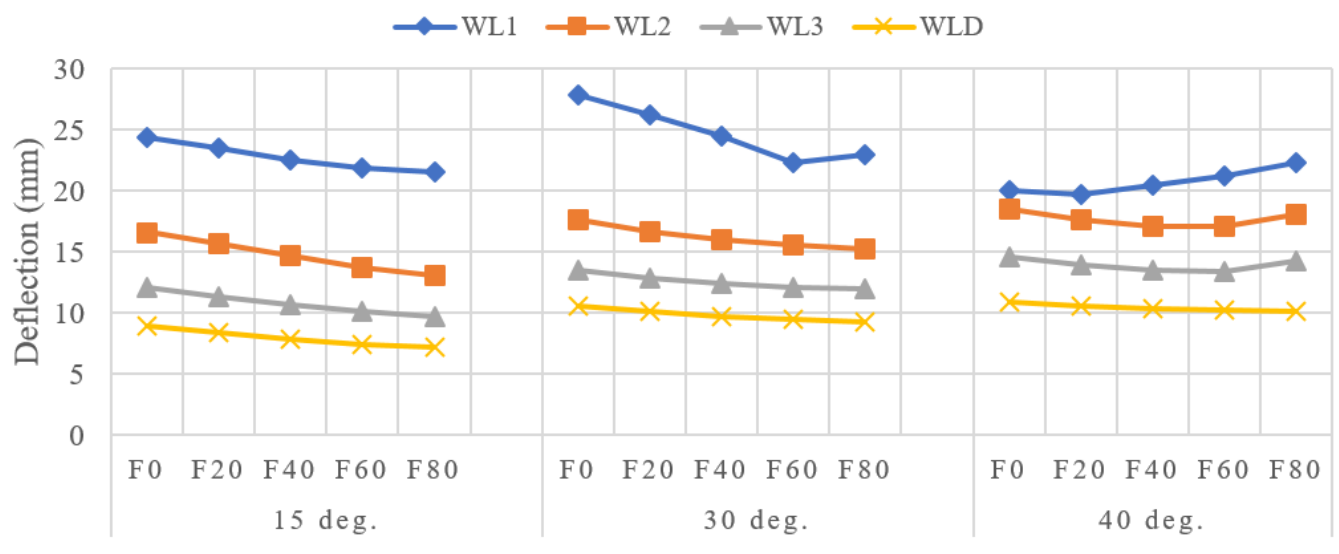

Anchor prestress

Figure 5. Variation of lateral deflection with anchor inclinations for $A 1$ and $L_{2}$

It is apparent that with increase in anchor inclinations, lateral deflection increases but with a reduced rate of increase. Also, the deflections decrease with increased anchor prestress. However, it should be noted that the rate of reduction decreases with the increase of anchor inclinations to such an extent that for the higher values of anchor inclinations, deflection increases even with increased anchor forces. The variations are more critical with different water table locations. For lower anchor inclinations $\left(15^{0}\right)$, wall deflection decreased with anchor force for all g.w.l locations considered. With the anchor inclination being increased to $30^{\circ}$, an increase in deflection is observed only for higher g.w.l case for the maximum anchor prestress considered. This shows that for ground conditions with higher water tables, it is unfavourable to use larger anchor inclinations. This is more evident with further increase of anchor inclination to $40^{\circ}$. Analysis with the three higher g.w.l locations showed increased deflections when combined with larger prestressing forces. Hence under this ground conditions, parameter combinations should be carefully chosen. Examples for effects of anchor prestress and inclinations are shown in Figure 6. It is apparent that for grounds with higher ground water level, use of larger anchor prestress will result in adverse results. This situation is more critical in combination with larger anchor inclinations and is evident from Figure 6(b) which shows that the combination of higher anchor force and inclination will result in undesirable results. Figures 7 and 8 shows effects of varying anchor length with prestressing force.

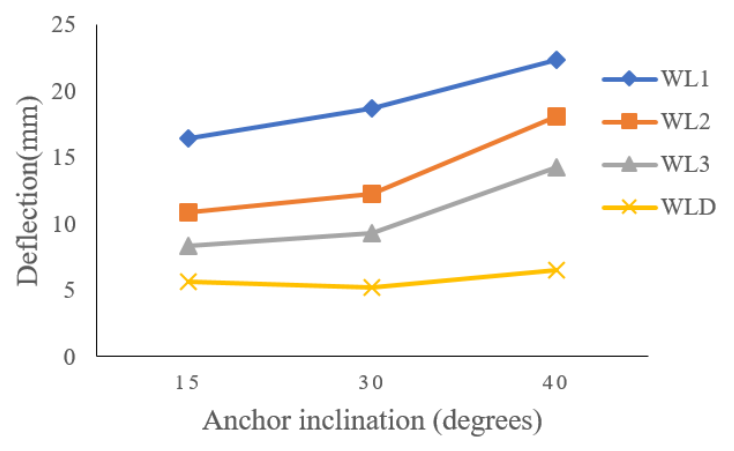

(a) $A 2$ and $F_{80}$

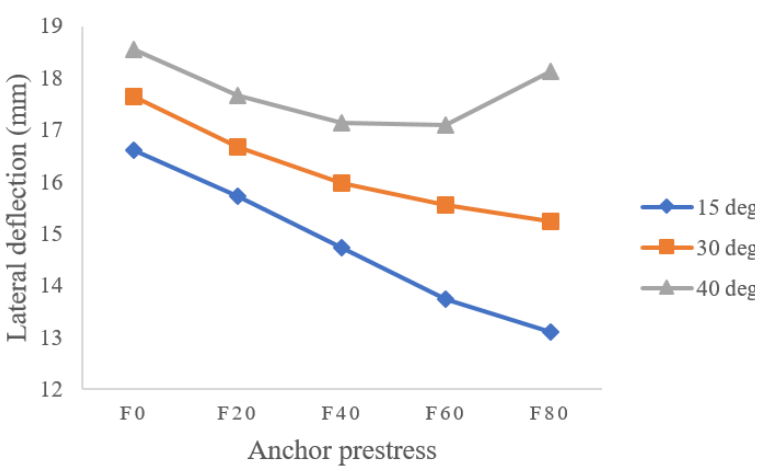

(b) $W_{L 2}$

Figure 6. Variation of lateral deflection with anchor inclinations 


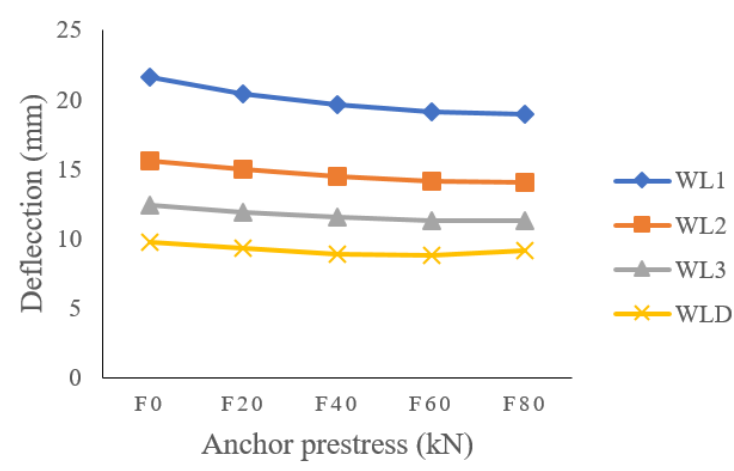

(a) Anchor inclination $30^{\circ}$

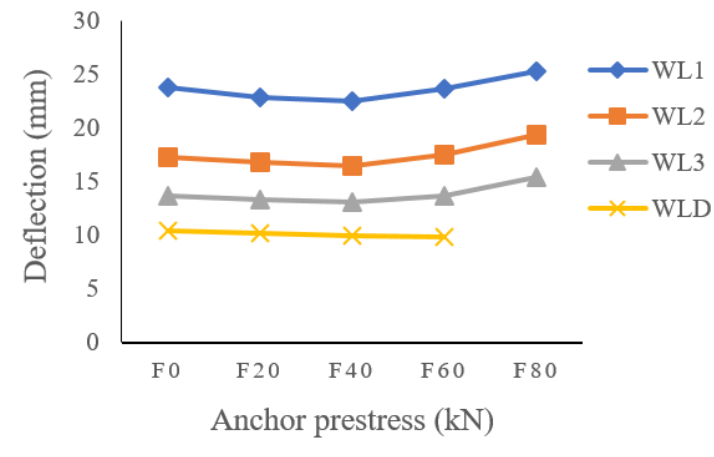

(b) Anchor inclination $40^{\circ}$

Figure 7. Variation of lateral deflection with anchor prestress for $\mathrm{Al}$ and $\mathrm{L}_{5}$

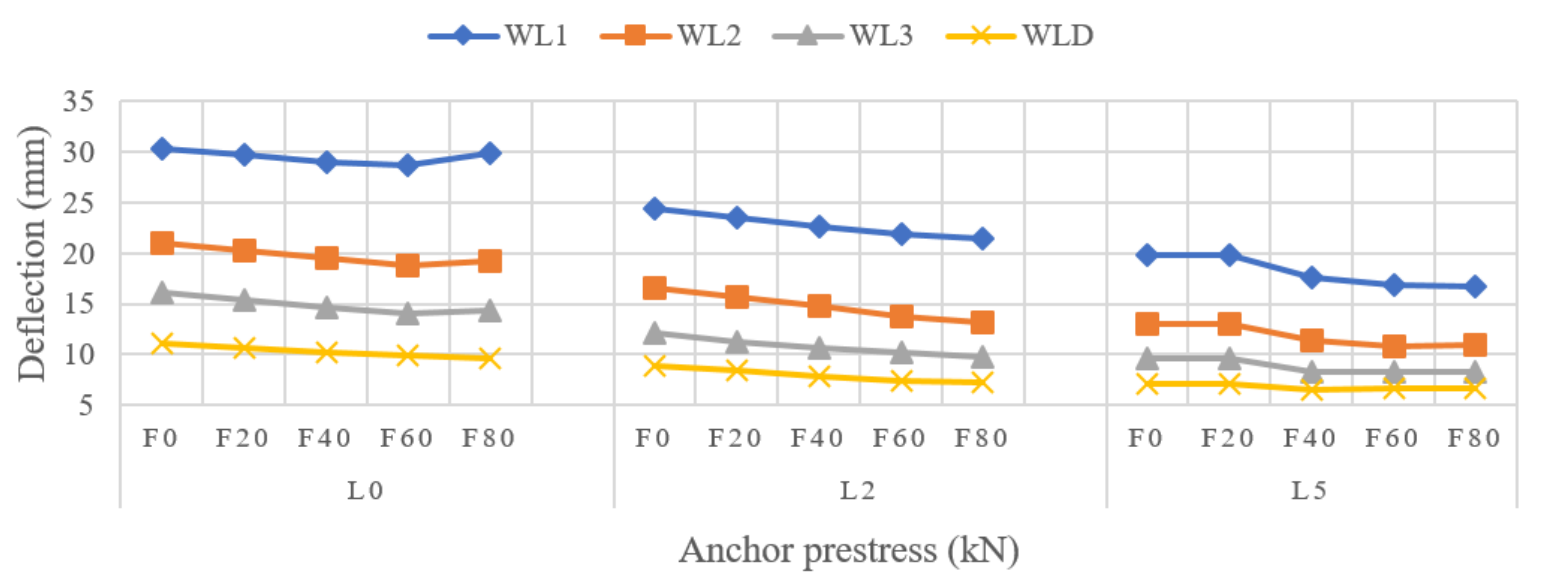

Figure 8. Variation of lateral deflection with anchor lengths for A1 and inclination $15^{\circ}$

\subsection{Effects on Axial Capacity of Retaining Structure}

Diaphragm walls being an embedded earth retaining structure, the vertical axial capacity should be given importance besides the flexural strength. The vertical forces acting on the wall arise from the combined effects of self-weight, resisting skin friction between wall and surrounding soil mass and the load components from the superstructure if the wall is acting as a part of foundation as well. For an anchored diaphragm wall, additional vertical forces will be induced from the vertical force components of inclined anchors. Hence the vertical axial capacity of walls, especially that for permanent anchored diaphragm walls which are being acted upon by force components from anchors should be carefully analysed. The axial forces from the numerical analysis of excavations supported by anchored diaphragm walls are presented in Figure 9.

For soil profile $\mathrm{A} 1$, when the anchor inclination increased from $15^{\circ}$ to $40^{\circ}$ with an anchor prestress of $F_{0}$, the axial force increased by $17.9 \%$ for $L_{0}$ and $13.07 \%$ for $L_{5}$. The corresponding variations for $F_{80}$ are $24.2 \%$ and $25.2 \%$. These variations are for the case of highest water table location considered, $W_{L 1}$. The corresponding variations for $W_{L D}$ are $67.3 \%, 24.35 \%, 33.33 \%$ and $40.7 \%$ respectively. For non-cohesive profiles, the increase of anchor inclination to $40^{\circ}$ from $15^{\circ}$ resulted in excavation failure for the combination of anchor length $L_{1}$ and prestress $F_{0}$. For anchor length $L_{3}$ the axial force increases by $22.32 \%$. For $F_{80}$ these variations are $26.22 \%$ and $36.06 \%$. The corresponding variations for $W_{L D}$ are $22.77 \%, 22.78 \%, 34.1 \%$ and $41.02 \%$. The general axial force variations with different anchor lengths, inclinations and prestressing forces for cohesive and non-cohesive soil profiles are shown in Figures 10 and 11 respectively. 


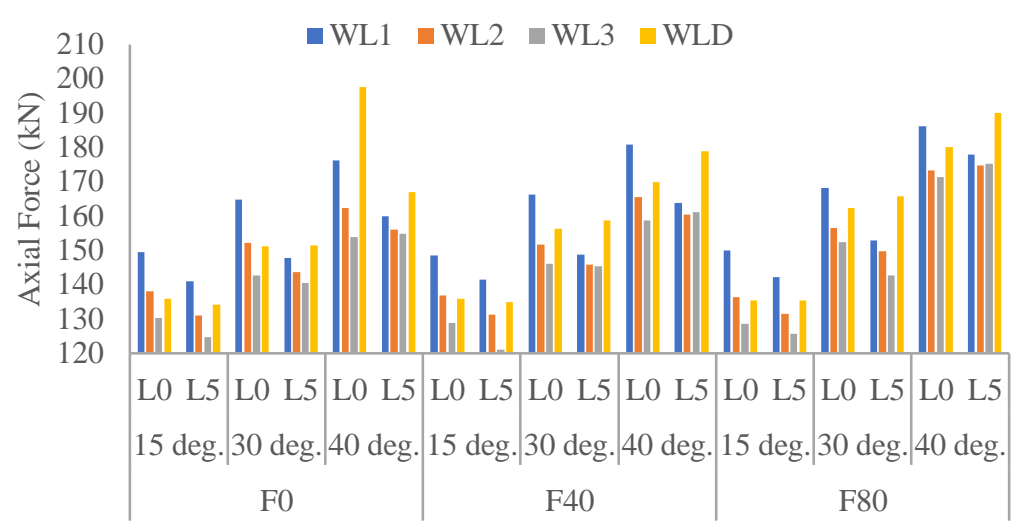

Figure 9. Axial force $(k N)$ for soil profile Al

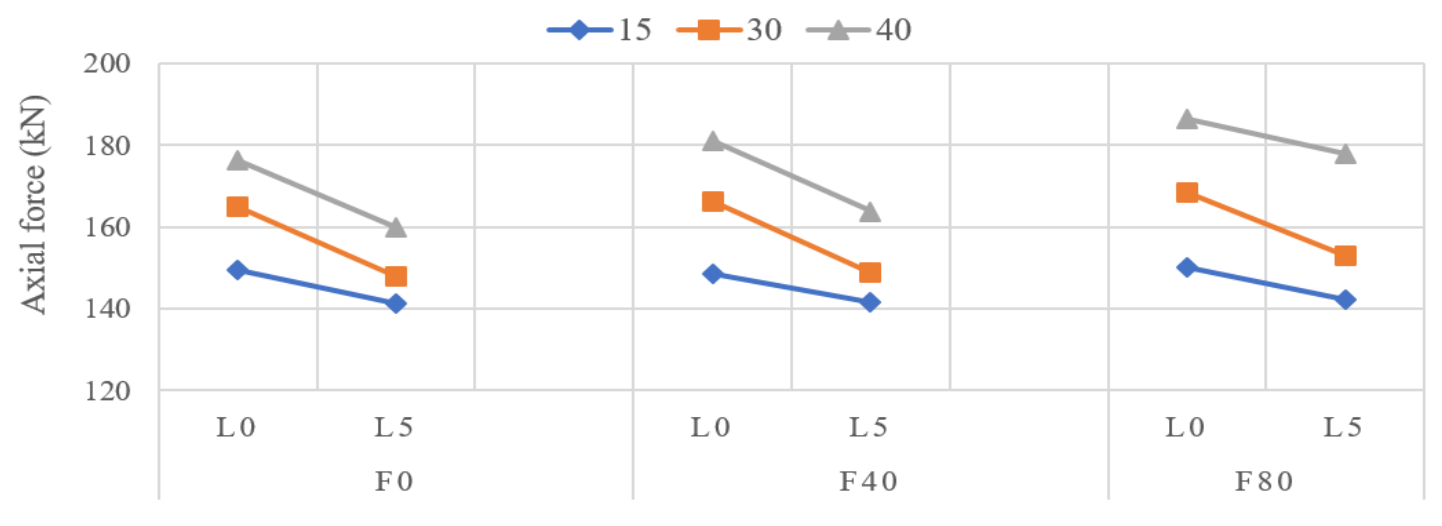

Anchor length

Figure 10. Axial force variation for cohesive soils with different parameters

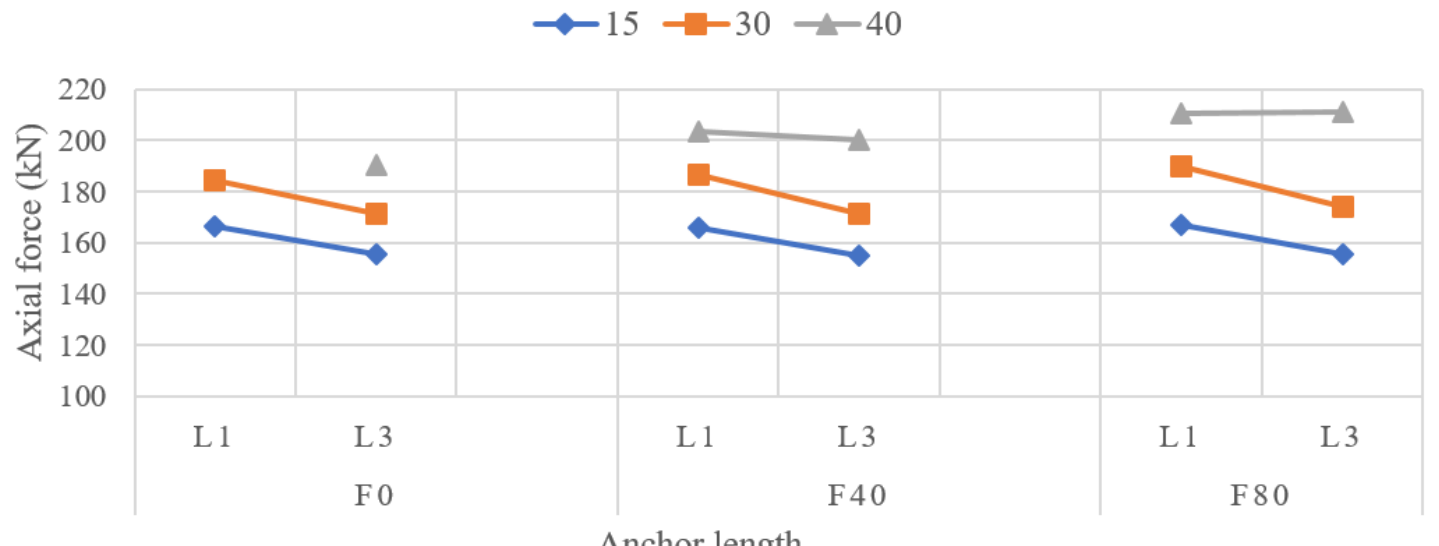

Figure 11. Axial force variation for non-cohesive soils with different parameters

The variations in axial force for a lower anchor inclination of $15^{0}$ is not much pronounced with respect to all the considered anchor prestress for both soil profiles. However, if the anchor inclination is further increased, it can be observed that axial force increases and is more for excavation cases with larger anchor prestressing forces. Comparable variations are observed for cohesion-less soils, with g.w.l below the subgrade levels. 
For unsaturated soils with g.w.l beyond the subgrade levels, it is observed unnecessary and unfavourable to use combinations of higher anchor length and inclinations as shown in Figure 12.

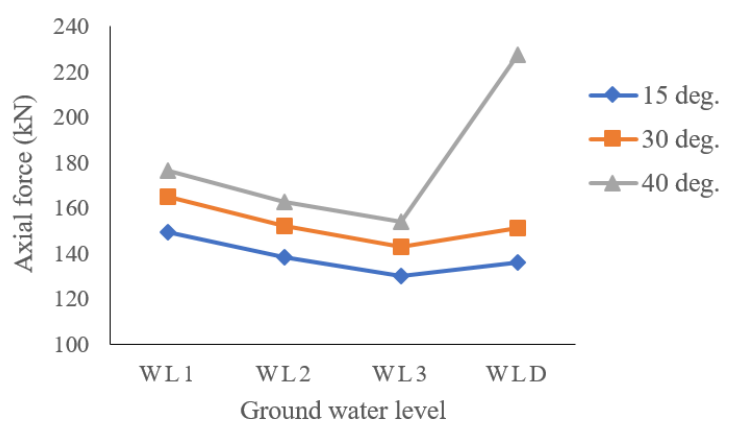

(a)

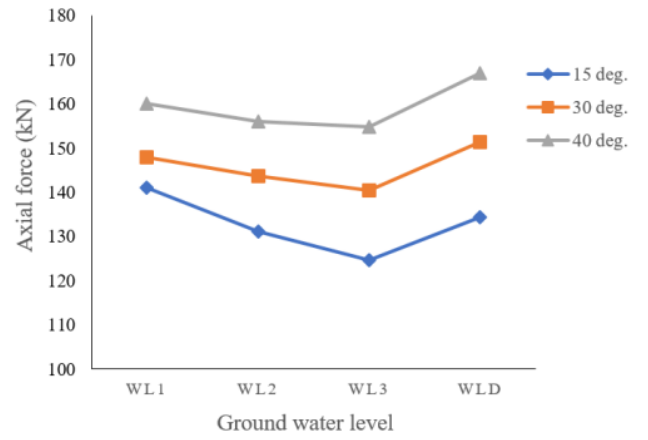

(b)

Figure 12. Axial force distributions with different g.w.l (a) $L_{0}(b) L_{5}$

\subsection{Effects on the Flexural Strength of Retaining Structure}

The flexural strength of deep retaining walls measured in terms of bending moments is an important factor for the design and must be critically evaluated. If the lateral displacements and corresponding bending moments are not within the safe limits, it may lead to the failure of the entire underground support system and consequently that of the neighbourhoods. A thorough knowledge of the possible bending moments which may develop on the retaining system can ensure safe combinations of preliminary geometric and support configurations. The numerical analysis carried out provides greater insights towards the possible development of flexural loads on the anchored diaphragm walls so as to highlight the optimal configurations. The resulting bending moments from the parametric analysis are given in Figure 13.
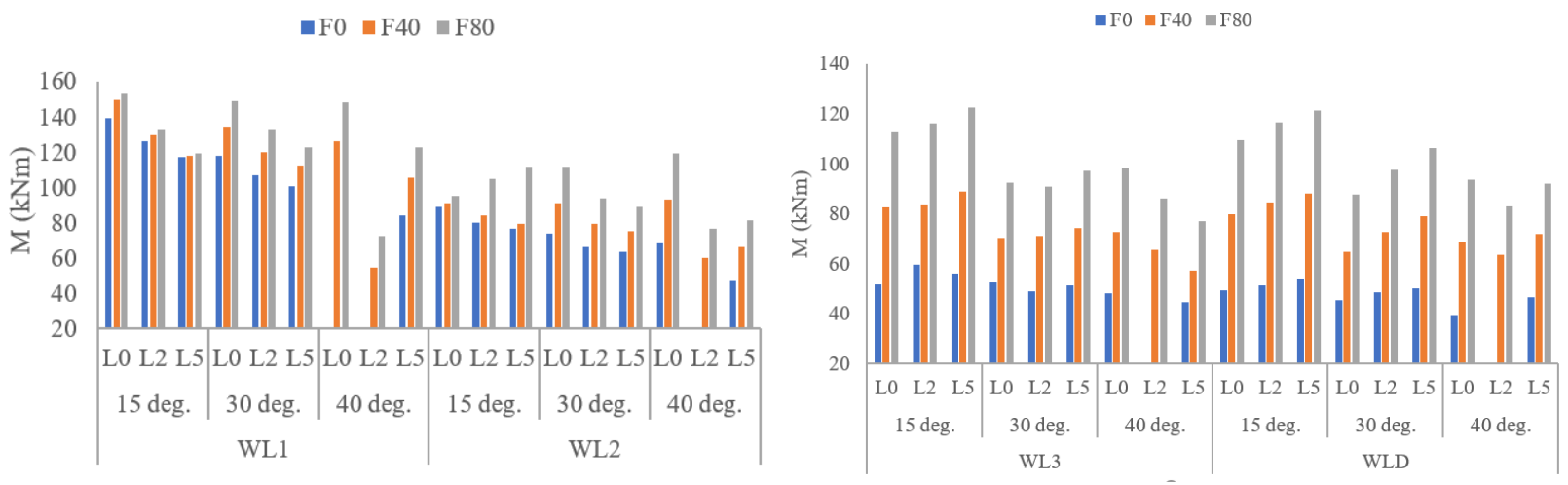

Figure 13. Bending moment (M) for soil profile A2

The general variation of bending moments with the combined effects of different parameters for anchor inclinations of $15^{\circ}$ and $30^{\circ}$ are given in Figures 14 and 15 respectively. Expected variations are observed for the minimum anchor length case considered. As the anchor length increased, and when combined with higher prestress cases, unfavourable variations occur except for the case with the highest water table. For this instance, as lateral loads are greater, need larger anchor lengths and anchor prestress and thereby give positive results. For the other situations, since lateral loads are lesser than the above due to the decrease in hydrostatic pressures, requirement of larger anchor length and prestress in not required and will result in increased bending moments. The rate of variations with increased anchor inclinations are evident from the combined evaluation of Figures 14 and 15. 


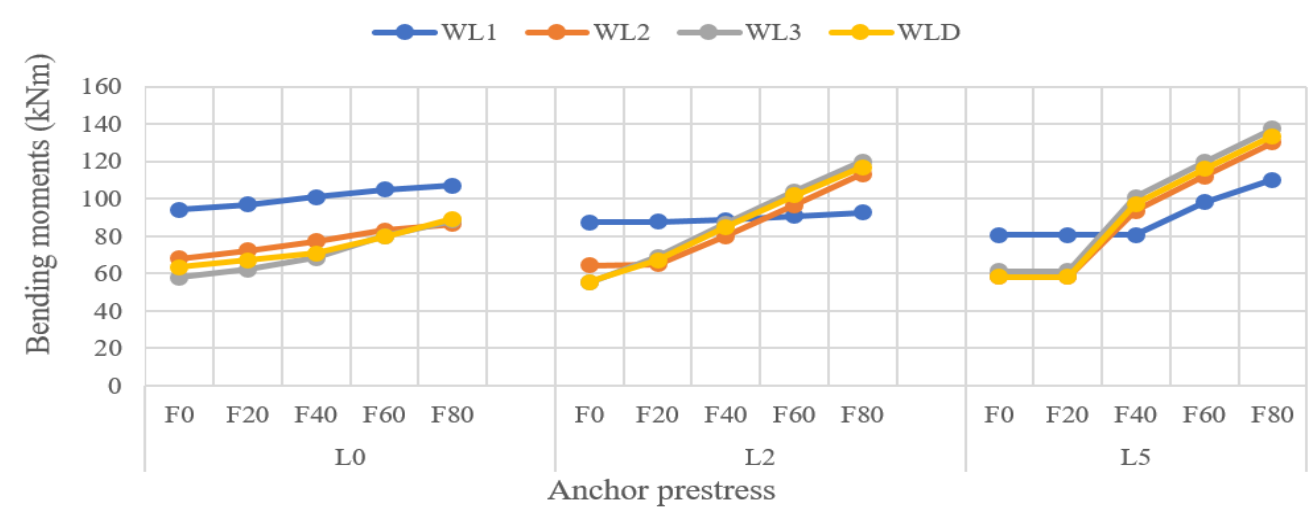

Figure 14. Variation in bending moments for an anchor inclination $15^{\circ}$ (Soil profile A1)

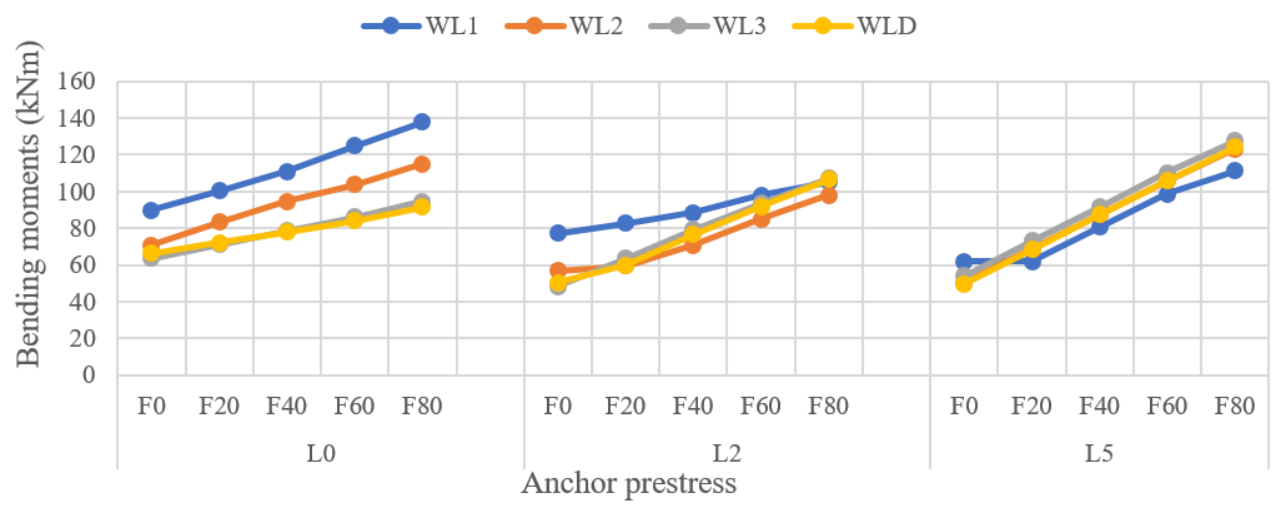

Figure 15. Variation in bending moments for anchor inclination $30^{\circ}$ (Soil profile A1)

In order to evaluate the influence of wall thickness on the diaphragm wall behaviours, certain parametric combinations are analysed for different wall thicknesses. Anchor inclinations of 15 degrees and 30 degrees with anchor lengths $L_{1}$ and $L_{3}$ in combination with prestressing forces $F_{40}$ and $F_{80}$ are considered. These combinations are again analysed for ground water levels, $W_{L 2}$ and $W_{L D}$ and the results are displayed in Table 6. Even though there are variations in bending moments and axial forces with different wall thicknesses, a pattern for the variations cannot be observed. Increase in wall thicknesses is found to have a positive influence of larger lateral loads, however cannot be generalised for all the parametric combinations. It if felt that detailed comprehensive analysis need to be performed to explicitly understand the influence of wall thickness on the responses in combinations with various other parameters.

Table 6. Variations with wall thickness

\begin{tabular}{|c|c|c|c|c|c|c|c|c|c|}
\hline \multirow{2}{*}{\multicolumn{2}{|c|}{$\begin{array}{l}\text { Anchor prestress } \\
\text { Anchor inclination }\end{array}$}} & \multicolumn{4}{|l|}{$F_{40}$} & \multicolumn{4}{|l|}{$F_{80}$} \\
\hline & & \multicolumn{2}{|l|}{15 deg. } & \multicolumn{2}{|l|}{30 deg. } & \multicolumn{2}{|l|}{15 deg. } & \multicolumn{2}{|l|}{30 deg. } \\
\hline g.w.1 & $d(\mathrm{~m})$ & $L_{1}$ & $L_{3}$ & $L_{1}$ & $L_{3}$ & $L_{1}$ & $L_{3}$ & $L_{1}$ & $L_{3}$ \\
\hline \multicolumn{10}{|c|}{ Axial force $(\mathrm{kN})$} \\
\hline \multirow{2}{*}{$W_{L D}$} & 0.8 & 144.00 & 139.02 & 164.60 & 159.10 & 143.72 & 138.68 & 168.50 & 164.70 \\
\hline & 1.0 & 151.11 & 150.52 & 161.50 & 161.50 & 151.11 & 150.52 & 161.50 & 161.25 \\
\hline \multirow{2}{*}{$W_{L 2}$} & 0.6 & 166.04 & 154.98 & 186.53 & 171.70 & 166.88 & 155.80 & 189.87 & 174.04 \\
\hline & 0.8 & 147.90 & 138.73 & 168.30 & 156.20 & 147.60 & 138.43 & 170.80 & 163.24 \\
\hline \multicolumn{10}{|c|}{ Bending moment $(\mathrm{kNm})$} \\
\hline \multirow{2}{*}{$W_{L D}$} & 0.8 & 079.59 & 088.17 & 064.69 & 079.00 & 109.43 & 121.37 & 087.57 & 106.39 \\
\hline & 1.0 & 094.90 & 096.09 & 104.64 & 103.07 & 094.90 & 096.09 & 104.64 & 103.07 \\
\hline \multirow{2}{*}{$W_{L 2}$} & 0.6 & 149.22 & 117.77 & 134.79 & 011.65 & 153.14 & 119.34 & 148.48 & 122.83 \\
\hline & 0.8 & 091.09 & 079.08 & 091.10 & 075.06 & 95.34 & 111.34 & 111.50 & 088.75 \\
\hline
\end{tabular}


When anchor length increases, the lateral deflection of diaphragm walls is found to decrease considerably. Similarly, the computed axial capacity also is found to be decreasing with increase in anchor lengths, but not always for higher installation angle of $40^{\circ}$. For certain parametric combinations with higher anchor inclinations and larger lengths, the axial capacity shows an opposite trend. For field conditions with higher ground water table, an increase in anchor length results in decreased bending moments, unless combined with higher prestressing loads and anchor inclinations. For combinations with lower lateral loads in terms of lower ground water table, the variations in bending moments cannot be generalised as decreasing with increased anchor length. Larger length is found to be an uneconomic combination resulting in adverse results for these cases.

For most of the combinations considered, especially for the cohesion-less soil, with increase in anchor inclinations, lateral deflections increased. However, an opposite tendency is found for the cohesive soil when the inclination increased from $15^{\circ}$ to $30^{\circ}$ and again increased for the anchor inclination of $40^{\circ}$ for fields with lower ground water levels. The axial force on walls increases with increase in anchor inclinations due to the larger vertical force components. For the soil profile A1, the bending moments are found to increase with increased anchor inclinations.

The increase in anchor prestress load will result in decreased lateral deflection, provided the system is composed of lower anchor inclinations. As the anchor inclinations increases, with higher prestressing forces, gradual increase in deflections are observed. The influence of anchor prestress on axial forces and bending moments depends on the other parametric combinations of anchor lengths, inclinations etc. This highlights the requirement of parametric analysis considering the combined influence of different factors affecting diaphragm wall stability.

\section{CONCLUSIONS}

Recognizing and understanding the factors affecting performance of diaphragm walls supporting deep excavations is a complex issue in the geotechnical field. This study attempts to quantitatively investigate the effects and combined effects of various parameters which influence a tie-back diaphragm wall. Plaxis $2 \mathrm{~d}$ is employed to analyse the different parameters and to estimate the significance of each.

Detailed parametric analysis was performed to quantify the influence of various features of anchored diaphragm walls. Parameters considered for the study include anchor configurations such as length, inclination and prestressing force and field properties. For accurate prediction of wall responses, it is necessary to understand how much these responses will vary with the combined effects of the influencing parameters. Each combination of varying parameters is analysed for four different ground water locations so that the response predictions are more practical. The results apparently showed that it is appropriate to include location of natural ground water as a varying parameter.

The quantitative variations of the effects of considered parameters on the deformations, axial capacity and flexural capacity of anchored diaphragm walls are determined. The lateral deflections and moments vary significantly with anchor inclinations. The variations are much pronounced for cases with high ground water levels. As the water level drops, the rate of variation lowers and is minimal for dry grounds. Study on length of anchor tendons gave expected results as decreased deflections with increased lengths. Ground responses shift to safer side with increase in anchor prestress force but only for the cases with higher lateral loads especially with larger hydrostatic pressures. For instances with lower lateral pressures, the combinations of higher lengths and larger prestress was found to be not only uneconomical but gave unfavourable results also. All these emphasises the necessity of analysis considering the combined influence of various factors of a diaphragm wall retaining system.

The variations in deflections, bending moments and axial forces with all the considered parameters are demonstrated in graphical plots. From these charts, ideal combinations of parameters suitable for preliminary dimensioning can be perceived easily for any particular diaphragm wall project. 


\section{CONFLICTS OF INTEREST}

No conflict of interest was declared by the authors.

\section{REFERENCES}

[1] Boscardin, M. D., and Cording, E. J., "Building response to excavation induced settlement", J. Geotech. Engg. Div., 115(1): 1-21, (1989).

[2] Clough, G., and Tsui, Y., "Performance of Tied-Back Walls in Clay", Journal of Geotechnical Engineering Division, 10 (12):1259-1273, (1989).

[3] Goh, A.," Assessment of basal stability for braced excavation system using finite element method", Comput Geotech, 10 (4): 325-338, (1990).

[4] Garvin, R., and Boward, J., "Using slurry walls to protect a historic building: a case study. Slurry walls: Design, Construction, and Quality Control", ASTM Special Topic Publication, 1129: 117-127, (1992).

[5] Winter, E., Skep, N., and Tallard, G., "Slurry wall performance Adjacent to Historic Church. Slurry wall: Design, Construction, and Quality Control”, ASTM STP, 1129: 164-171, (1992).

[6] Ou, C., Hsieh, P., and Chion, D., "Characteristics of ground surface settlement during excavation", Can Geotech J, 30 (5): 758-767, (1993).

[7] Wong, I., Poh, T., and Chuah, H., "Analysis of case histories from construction of the Central Expressway in Singapore”, Can Geotech J., 33 (5): 732-746, (1996).

[8] Yajnheswaran, B., Ranjan, H. S., and Rao, S., "Analysis of the effect of anchor rod on the behavior of diaphragm wall using plaxis 3d", Aquatic Procedia 4: 240-247, (2015).

[9] Yajnheswaran, B., Akshay, P. R., Rajasekaran, C. and Rao, S., "Effect of stiffness on performance of diaphragm wall”, Procedia Engineering, 116: 343-349, (2015).

[10] Lewandowska, A. S. and Czajewska, M. M., "Design of diaphragm walls according to EN 19971:2004 Eurocode 7", Proceedings of the 14th European Conference on Soil Mechanics and Geotechnical Engineering, 291-296, (2007).

[11] Ou, C. Y., Deep excavation: Theory and practice, CRC Press, Great Britain, (2006).

[12] Sabatini, P. J., Pass, D. G. and Bachus, R. C., "Ground anchors and anchored systems", Federal Highway Administration- Office of Bridge Technology, No. FHWA-IF-99-015, United States, (1999).

[13] Teo, P. L. and Wong, K. S., "Application of the Hardening Soil model in deep excavation analysis", The IES Journal Part A: Civil \& Structural Engineering, 5(3): 152-165, (2012).

[14] Hoe, N. G., "Numerical modeling of diaphragm wall in Kuala Lumpur limestone formation", Faculty of Civil Engineering, University Teknology, Malaysia, (2007).

[15] Ghobrial, F., Fayed, A., Morsy, M. and Karray, M., "Numerical analysis of the effect of wall roughness in deep excavations in sand", International Journal of Geotechnical Engineering, 5(3): 315-327, (2011). 
[16] Goh, A. T., "Basal heave stability of supported circular excavations in clay", Tunnelling and Underground Space Technology, 61: 145-149, (2017).

[17] Bahrami, M., Khodakarami, M. I. and Haddad, A., "3D numerical investigation of the effect of wall penetration depth on excavations behavior in sand", Computers and Geotechnics, 98: 82-92, (2018).

[18] Chehadeh, A., Turan, A., Abed, F. and Yamin, M., "Lateral earth pressures acting on circular shafts considering soil-structure interaction”, International Journal of Geotechnical Engineering, 13(2): 139151, (2019).

[19] Houhou, M. N., Emeriault, F. and Belounar, A., "Three-dimensional numerical back-analysis of a monitored deep excavation retained by strutted diaphragm walls", Tunnelling and Underground Space Technology, 83: 153-164, (2019).

[20] Mitew-Czajewska, M., "A study of displacements of structures in the vicinity of deep excavation", Archives of Civil and Mechanical Engineering, 19(2): 547-556, (2019).

[21] Hsiung, B. C. B., Yang, K. H., Aila, W. and Hung, C., "Three-dimensional effects of a deep excavation on wall deflections in loose to medium dense sands", Computers and Geotechnics, 80: 138-151, (2016). 